\title{
PENERAPAN PERMAINAN LEGO KIMIA SEBAGAI MEDIA PEMBELAJARAN SUB MATERI KONFIGURASI ELEKTRON TERHADAP HASIL BELAJAR SISWA KELAS X SMA NEGERI 2 MADAT KABUPATEN ACEH TIMUR
}

\author{
Mutia Wati \\ SMA Negeri 2 Madat Kabupaten Aceh Timur \\ Bintah, Madat, Kabupaten Aceh Timur, Aceh 24394 \\ Email: watimutia075@gmail.com
}

\begin{abstract}
Abstrak
Penelitian ini bertujuan untuk mendeskripsikan peningkatan hasil belajar kimia pada pokok bahasan konfigurasi elektron dengan penerapan permainan lego pada siswa kelas X. MIA SMA Negeri 2 Madat. Penelitian dilaksanakan di SMA Negeri 2 Madat dengan jumlah sampel sebanyak 24 orang, 13 orang berjenis kelamin perempuan dan 11 orang berjenis kelamin laki-laki. Metode penelitian menggunakan penelitian tindakan kelas yang terdiri dari pra siklus, siklus I dan siklus II. Teknik pengumpulan data menggunakan tes hasil belajar yang diberikan pada awal dan akhir pembelajaran. Teknik analisis data menggunakan $\mathrm{N}$-gain dengan membandingkan data pretest dan posttest siklus I dan II untuk melihat peningkatan hasil belajar melalui penerapan permainan lego kimia. Berdasarkan hasil penelitian, hasil tes belajar siswa diperoleh nilai skor rata-rata tes awal untuk prasiklus, siklus I dan siklus II yaitu 55, 60 dan 72,4 dan skor rata-rata tes akhir untuk prasiklus, siklus I dan siklus II yaitu 70, 85 dan 91,3 selanjutnya untuk peningkatan hasil belajar melalui silus I dan II diperoleh nilai Ngain 0,68 atau berkategori sedang dan 0,75 berkategori tinggi. Melalui penerapan permainan lego kimia siswa menjadi lebih aktif dan mampu memecahkan permasalahan tentang konfigurasi elektron.
\end{abstract}

Kata Kunci : Lego Kimia, Media Pembelajaran, Konfigurasi Elektron

\begin{abstract}
This study aims to describe the improvement of chemistry learning outcomes on the subject of electron configuration with the application of lego games in class X. MIA SMA Negeri 2 Madat. The research was conducted at SMA Negeri 2 Madat with a total sample of 24 people, 13 were female and 11 were male. The research method used classroom action research consisting of pre-cycle, cycle I and cycle II. The data collection technique uses a learning outcome test given at the beginning and end of the lesson. The data analysis technique used $N$-gain by comparing the pretest and posttest data in cycles I and II to see an increase in learning outcomes through the application of chemical lego games. Based on the results of the study, the results of student learning tests obtained the mean score of the initial test for pre-cycle, cycle I and cycle II, namely 55, 60 and 72.4 and the average score of the final test for pre-cycle, cycle I and cycle II is 70. 85 and 91.3 furthermore to improve learning outcomes through silus I and II obtained an N-gain value of 0.68 or in the medium category and 0.75 in the high category. Through the application of the chemistry lego game students become more active and able to solve problems about electron configuration.
\end{abstract}

Keywords: Lego Chemistry, Learning Media, Electron Configuration

PENDAHULUAN

Mata pelajaran kimia merupakan mata pelajaran yang terintegrasi dengan pembelajaran IPA dan diberikan secara menyeluruh di bangku SMA. Selain merupakan materi baru yang butuh pendalaman, ini juga merupakan kesempatan bagi guru mata pelajaran kimia untuk memberikan kesan awal yang baik terhadap siswa. Materi kimia termasuk 
materi yang cukup sulit bagi siswa dikarenakan konsep yang diberikan banyak bersifat abtrak (Yumna, 2017). Materi pelajaran kimia yang bersifat abstrak diantaranya struktur atom, partikel atom, partikel materi, ikatan kimia dan mekanisme reaksi. Materi ini merupakan materi dasar dan materi utama dari konsep kimia. Jika materi ini tidak dapat dikuasai, maka siswa akan sulit memahami tentang pembentukan unsur dan molekul serta sifatsifat unsur dalam tabel periodik. Konsepkonsep ini merupakan konsep yang abstrak, perlu pemahaman yang mendalam untuk memahaminya (Magdalena, 2017).

Selama ini materi konfigurasi elektron hanya dijelaskan melalui ceramah dan media papan tulis, konsep yang dijelaskan tidak keseluruhan dan siswa cenderung sulit memahami penjelasan yang diberikan (Sadiman, 2010). Penggunaan media menjadi sangat penting dalam proses pembelajaran, karena tanpa media proses belajar mengajar tidak berjalan lancar (Widiadi, 2016). Guru harus mampu memvariasikan penggunaan media agar minat siswa menjadi lebih baik (Magdalena, 2017). Penggunaan media pembelajaran mampu membuat siswa lebih bisa memahamai konsep kimia terutama yang bersifat abstrak (Shelawaty, 2016). Oleh karena itu, diperlukan media pembelajran yang menarik khususnya pada sub materi konfigurasi elektron. Media merupakan salah satu solusi untuk meminilmalisir keterbatasan waktu dalam mengajar (Yektyastuti \& Ikhsan, 2016). Salah satu media yang mampu menyampaikan materi secara menarik dan efektif adalah media permainan. Penggunaaan media permainan ternyata efektif dalam meningkatkan hasil belajar siswa pada pelajaran kimia dengan ketuntasan sebesar 94,44 \% (KKM 75) (Pramita, 2016). Permainan menggunakan media bongkar pasang terbukti dapat meningkatkan hasil belajar kimia siswa meningkat menjadi sangat baik yaitu 92,20 \% (Magdalena, 2017). Salah satu alternatif permainan yang dapat dijadikan media pembelajaran adalah lego (Juniarni, dkk., 2019). Lego adalah sejenis alat permainan balok yang terbuat dari plastik kecil dengan bentuk yang berbeda-beda dan bisa dimainkan oleh semua kalangan dan menjadi salah satu permainan yang terkenal di dunia (Kartini dan Susilawati, 2018).

Lego merupakan permainan konstruktif dan juga produktif sehingga dapat memunculkan kreativitas siswa dan membangun kerjasama, serta memfasilitasi siswa untuk lebih berkonsentrasi pada proses pembelajaran (Nath, 2014). Kegiatan dalam permainan lego dapat menumbuhkan kreatifitas dan mengembangkan imajinasi sesorang (Rejeki, 2016).

Pengembangan media lego dalam pembelajaran kimia sudah pernah dilakukan namun untuk melihat peningkatan hasil belajar terutama dalam kimia belum pernah dilakukan. Untuk itu, dalam penelitian ini akan diterapkan permainan lego kimia sub materi konfigurasi elektron yang dikolaborasikan dengan beberapa set kartu soal yang pernah dilakukan oleh (Juniarni, dkk., 2019) untuk peningkatan hasil belajar siswa kimia di SMA Negeri 2 Madat Kabupaten Aceh Timur.

\section{METODE PENELITIAN}

Penelitian menggunakan metode penelitian tindakan kelas dimana melihat peningkatan hasil belajar siswa melalui penerapan permainan lego kimia melalui 
beberapa siklus. Setiap masing-masing siklus (pra siklus, siklus I dan siklus II) terdiri atas perencanaan pembelajaran, pelaksanaan pembelajaran, pengamatan dan refleksi.

Subjek dalam penelitian ini terdiri dari populasi yaitu seluruh siswa X MIA, sampel penelitian yaitu SMA Negeri 2 Madat kelas X MIA-1 yang berjumlah 24 orang terdiri dari 13 perempuan dan 11 lakilaki. Teknik sampling yang digunakan dalam penelitian ini adalah purposive sampling, dengan pertimbangan hasil diskusi bersama guru kimia kelas X SMA Negeri 2 Madat.

Teknik pengumpulan data menggunakan data hasil tes tertulis.Tes tertulis diberikan pada setiap akhir siklus.

Teknik analisis data untuk melihat peningkatan dari hasil belajar siswa yang ditinjau dari prê test dan post test siklus I dan II. Hasil peningkatan belajar siswa kemudian dihitung dengan skor gain pada Persamaan 1.

$$
N \text {-Gain }=\left[\frac{N_{B-N_{A}}}{N_{M A X}-N_{A}}\right] X 100 \% .
$$

Keterangan:

$\mathrm{N}_{\mathrm{A}} \quad=$ nilai awal

$\mathrm{N}_{\mathrm{B}} \quad=$ nilai akhir

$\mathrm{N}_{\text {MAX }}=$ nilai ideal

Hasil belajar dikatakan meningkat jika memperoleh hasil skor gain minimal 0,7 dengan kriteria tinggi. Skor gain dapat disesuaikan dengan criteria seperti pada Tabel 1 (Munandar, 2009):

Tabel 1. Kriteria skor n-Gain

\begin{tabular}{ll}
\hline $\begin{array}{l}\text { Skor Gain } \\
\text { peningkatan }\end{array}$ & Kriteria \\
\hline $\mathrm{g} \geq 0,7$ & Tinggi \\
\hline $0,7>\mathrm{g} \geq 0,3$ & Sedang \\
\hline $\mathrm{g}<0$, & Rendah \\
\hline
\end{tabular}

\section{HASIL DAN PEMBAHASAN}

Berdasarkan hasil kemampuan awal siklus 1 dan 2 dapat terlihat adanya perbedaan jumlah siswa yang masih di bawah Kriteria Ketuntasan Minimal. Pada siklus I, nilai pretest siswa sebanyak 55 (prasiklus), 60 ( siklus I) dan 72,4 (siklus II). Untuk jumlah siswa yang dibawah KKM sebanyak 18 siswa $(87,5 \%)$ dan pada akhir siklus 1 berkurang menjadi 15 siswa $(65,0 \%)$ sedangkan pada akhir siklus 1I siswa yang masih mempunyai nilai di bawah KKM (70) hanya 8 siswa $(27,5 \%)$. Hasil data posttest sebesar 70 (prasiklus), 85 (siklus I) dan 91,3 (siklus II). Jumlah siswa yang mencapai ketuntasan belajar DI siklus II mengalami peningkatan jika dibandingkan dengan siklus 1, seperti disajikan dalam Tabel 2. berikut ini.

Tabel 2. Perbandingan Hasil Nilai Tes awal dan tes akhir Prasiklus ,Siklus 1 dan Siklus 2

\begin{tabular}{|c|c|c|c|c|}
\hline \multirow{2}{*}{ No } & Hasil & \multicolumn{3}{|c|}{ Nilai siswa } \\
\cline { 3 - 5 } & tes & $\begin{array}{c}\text { Pra } \\
\text { siklus }\end{array}$ & $\begin{array}{c}\text { Siklus } \\
1\end{array}$ & $\begin{array}{c}\text { Siklus } \\
2\end{array}$ \\
\hline 1. & Pretest & 55 & 60 & 72,4 \\
\hline 2. & Posttest & 70 & 85 & 91,3 \\
\hline
\end{tabular}

Selanjutnya untuk data peningkatan hasil belajar menggunakan $\mathrm{N}$-gain diperoleh nilai sebesar 0,68 atau berkategori sedang untuk siklus I dan 0,75 dengan kriteria tinggi untuk siklus II. Hasil analisis data penelitian tersebut membuktikan adanya peningkatan yang signifikan mengenai hasil belajar siswa sebelum dan sesudah menggunakan media lego kimia. Penggunaan media lego kimia terbukti lebih mampu untuk meningkatkan hasil belajar siswa terutama pada materi 
konfigurasi elektron. Hal ini terlihat bahwa ketika mengerjakan soal yang berhubungan dengan konfigurasi ssiwa sudah tau membedakan masing-masing subkulit dan kulit. Sebelum menggunakan media permainan lego siswa cenderung mengobrol dan sulit menyelesaikan soal yang diberikan guru. Media pembelajaran Ini sangat penting karena dapat memberikan dampak yang signifikan terhadap aktivitas mengajar di kelas. Dampaknya berkembang dari hari ke hari dan dosen serta mahasiswa terpengaruh oleh dampak karena dengan penggunaan media peserta dapat saling berdiskusi, memperkuat aktivitas kelas, mengaktifkan pembelajaran serta menciptakan kolaborasi diantara sesamanya. Hal ini sejalan dengan penenitian (Hassan dkk,. 2014) yaitu media permainan juga dapat digunakan dalam pembelajaran di dalam maupun di luar waktu belajar, karena penggunaannya yang fleksibel. Adapun bentuk permainan lego kimia yang diberikan kepada siswa dapat dilihat pada Gambar 1.

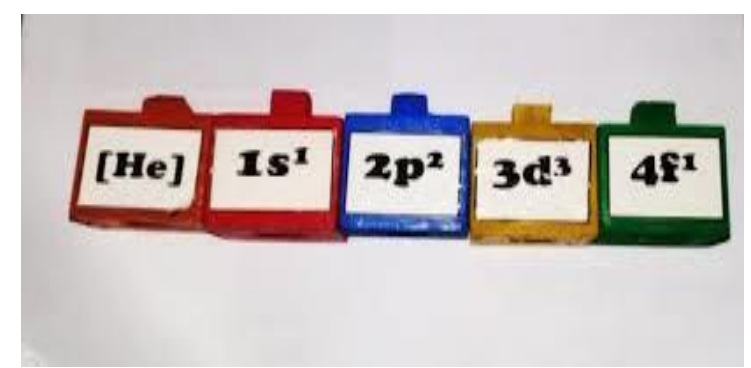

Gambar 1. Bentuk Permainan Lego Kimia Konfigurasi Elektron

Media pembelajaran permainan lego kimia yang digunakan untuk meningkatkan motivasi belajar dan prestasi kognitif peserta didik telah melalui tahap validasi oleh ahli media dan ahli materi, evaluasi oleh pendidik kimia dan peer reviewer, uji coba perorangan, uji coba kelompok kecil dan uji coba lapangan (Juniarni, dkk., 2019).

Media pembelajaran permainan lego kimia memiliki tampilan visualisasi yang menarik, gampang dibuat, praktis dan fleksibel yang dapat digunakan kapan dan di mana saja, serta mampu membuat evaluasi soal yang variatif, sehingga peserta didik dapat mengulang materi secara mandiri tanpa terikat waktu dan tempat serta mampu meningkatkan daya ingat terhadap materi yang disampaikan. Pernyataan ini sesuai dengan hasil penelitian Sakat et al. (2012) bahwa dengan menggunakan media pembelajaran berbasis teknologi dapat meningkatkan motivasi, karena pembelajaran lebih aktif, sehingga pembelajaran menjadi lebih menarik dan menyenangkan.

Berdasarkan hasil penelitian dapat disimpulkan bahwa media pembelajaran permainan lego kimia dapat digunakan sebagai alternatif media pembelajaran kimia yang dapat meningkatkan hasil belajar SMA. Kelebihan yang menonjol dari media pembelajaran lego kimia ini adalah keluwesannya untuk dapat digunakan di mana saja dan kapan saja tanpa terikat ruang dan waktu. Kelebihan ini didukung oleh perangkat permainan yang ukurannya kecil, ringan, dan mudah dibawa kemana saja.

\section{KESIMPULAN DAN SARAN Kesimpulan}

Pada siklus I, nilai pretest siswa sebanyak 55 (prasiklus), 60 ( siklus I) dan 72,4 (siklus II). Untuk jumlah siswa yang dibawah KKM sebanyak 18 siswa $(87,5 \%)$ dan pada akhir siklus 1 berkurang menjadi 15 siswa $(65,0 \%)$ sedangkan pada akhir siklus 1I siswa yang masih mempunyai nilai di bawah KKM (70) hanya 8 siswa 
(27,5\%). Hasil data posttest sebesar 70 (prasiklus), 85 (siklus I) dan 91,3 (siklus II). Jumlah siswa yang mencapai ketuntasan belajar DI siklus II mengalami peningkatan jika dibandingkan dengan siklus 1 . Selanjutnya untuk peningkatan hasil belajar melalui silus I dan II diperoleh nilai $\mathrm{N}$-gain 0,68 atau berkategori sedang dan 0,75 berkategori tinggi.

\section{Saran}

Berdasarkan hasil penelitian dan pengembangan yang telah dilakukan saran yang dapat peneliti sampaikan yaitu evaluasi soal yang akan digunakan harap disiapkan sebelum melakukan pembelajaran agar soal yang diberikan lebih bervariasi.

\section{DAFTAR PUSTAKA}

Hassan, S.M., Azhar, T., Hassan, T., \& Hassan, S.H., 2014. Using Social Media to Maximaze Students' Learning Outcames. Journal of Education and Practice. 5 (23). 157-159.

Juniarni, D. I., Fadhilah, R. \& Kurniawan, R. A. 2019. Pengembangan Permainan Lego Kimia Sebagai Media Pembelajaran Sub Materi Konfigurasi Elektron Pada Siswa Kelas X SMA Muhammadiyah 1 Pontianak. Ar-Razi Jurnal Ilmiah. Vol. 7. No. 1. Hal. 47-55.

Kartini dan Susilawati, I. 2018. Pengaruh Media Pembelajaran Lego Untuk Meningkatkan Kreativitas Anak Usia Dini. Jurnal Pendidikan Anak Usia Dini, Vol. 1, No. 2.

Magdalena, Z. 2017. Penerapan Metode Simulasi Berbantuan Media Bongkar Pasang Konfigurasi Elektron Untuk Meningkatkan Aktivitas dan Hasil Belajar Siswa pada Materi Konfigurasi Elektron dan Sistem Periodik Unsur di Kelas X MIA SMAN 2 Madat kuantum (Jurnal Inovasi Pendidikan Sains).5(1).

Maike, S. T. 2008. Bermain ,Mainan dan Permainan untuk Anak Usia Dini .Jakarta: Grasindo.

Mulyatiningsih, E. 2012. Metode Penelitian Terapan Bidang Pendidikan. Bandung: Penerbit Alfabeta.

Munandar, U. 2009. Pengembangan Kreativitas Anak Berbakat. Jakarta: Rineka Cipta

Nath, S., \& Szucs, D. 2014. Constuction Play Cognitive Skills Associated With The Development of Mathematical Abilities in 7-YearOld Children. Learning and Instruction. 3(2).

Pramita, A,. \& R. Agustini. 2016. Pengembangan Media Permainan Ular Tangga pada Materi Senyawa Hidrokarbon Kelas XI SMA untuk Meningkatkan Pemahaman Konsep Siswa. Unesa Journal of Chemical Education.5(2).

Rejeki, S., N. Setyaningsih \& M. Toyib. 2016. Optimalisasi Penggunaan Lego dalam Pembelajaran Matematika SMP untuk Mendukung Implementasi Kurikulum 2013. WartaLPM.19(2).

Sadiman, A. S. 2010. Media Pendidikan: Pengertian, Pengembangan Dan Pemanfaatannya. Jakarta: PT Rajagrafindo Persada.

Sakat, A. A., Mohd Zin, M. Z., Muhamad, R., Ahmad, A., Ahmad, N. A., \& Kamo, M. A. 2012. Educational technology media method in teaching and learning progress. American Journal of Applied Sciences , 874-888. 
Shelawaty, A. R., Hadiarti, D \& Fadhilah, R. 2016. Pengembangan Media Flash Materi Ikatan Kimia Siswa Kelas X SMA Negeri 1 Pontianak. Ar-Razi Jurnal Ilmiah. 4 (2).

Widiadi, A.N. 2016. Pengembangan Aplikasi Ruang Kuliah Android (Arka) Untuk Matakuliah Penelitian Pendidikan Sejarah. Jurnal Pendidikan dan Sejarah. 10 (1). 111.

Yektyastuti, R., \& Ikhsan, J., 2016. Pengembangan Media Pembelajaran Berbasis Android Pada Materi Kelarutan Untuk Meningkatkan Performa Akademik Peserta Didik SMA. Jurnal Inovasi Pendidikan IPA. 5(1). 88-99. http://journal.uny.ac.id/index.php/ji pi

Yumna, Y., Cawang \& Hadiarti, D. 2017. Pengaruh Model Pembelajaran Kooperatif Tipe TAI (Team Asissted Individualization) Berbantuan Video terhadap Hasil Belajar Siswa pada Sub Materi Konfigurasi Elektron Kelas X SMA Negeri 5 Pontianak. Ar-Razi Jurnal Ilmiah. 5 (2). 